\title{
Theoretical investigation of an in situ k-restore process for damaged ultra-low-k materials based on plasma enhanced fragmentation
}

\author{
Anja Förster*, ${ }^{*}$, Christian Wagner\#, Sibylle Gemming ${ }^{+, \$, \dagger}$, Jörg Schuster* \\ * Fraunhofer ENAS, Technologie-Campus 3, 09126 Chemnitz, Germany \\ \# Center for Microtechnologies, TU Chemnitz, Reichenhainer Str. 70, 09126 Chemnitz, Germany \\ + Department of Physics, TU Chemnitz, Reichenhainer Str. 70, 09126 Chemnitz, Germany \\ $\$$ Helmholtz-Zentrum Dresden-Rossendorf, Institute of Ion Beam Physics and Materials Research, \\ Bautzner Landstraße 400, 01328 Dresden, Germany and \\ $\dagger$ Center for Advancing Electronics Dresden, TU Dresden, 01062 Dresden, Germany
}

\begin{abstract}
We present theoretical investigations of a k-restore process for damaged pourous ultra-low-k (ULK) materials. The process is based on plasma enhanced fragmented silylation precursors to replace k-value damaging, polar $\mathrm{Si}-\mathrm{OH}$ and $\mathrm{Si}-\mathrm{H}$ bonds by k-value lowering $\mathrm{Si}_{-} \mathrm{CH}_{3}$ bonds. We employ density functional theory (DFT) to determine the favored fragments of silylation precursors and show the successful repair of damaged bonds on our model system. This model system consists of a small set of ULK-fragments which represent various damaged states of ULK materials. Our approach provides a fast scanning method for a wide variety of possible repair reactions. Further, we show that oxygen containing fragments are required to repair $\mathrm{Si}-\mathrm{H}$ bonds and fragments with dangling Si-bonds are most effective to repair polar $\mathrm{Si}-\mathrm{OH}$ bonds.
\end{abstract}

\section{INTRODUCTION}

The ongoing miniaturization process in the microelectronic industry [1] has led to the use of ultra-low-k (ULK) dielectrics in the on-chip interconnect system. They owe their low dielectric constant (k-value) to pores 2-4 and terminal hydrophobic organic species [5] such as methyl groups. During the manufacturing process of integrated circuits (ICs), the k-value of the ULK materials increases. This is due to the loss of methyl groups which are replaced by hydrophilic, polar groups generated by active radicals and highly energetic vacuum-ultra-violet photons that break $\mathrm{Si}-\mathrm{CH}_{3}$ bonds 6. In particular, $\mathrm{Si}-\mathrm{H}$ bonds are formed (H-damage), which can create $\mathrm{Si}-\mathrm{OH}$ bonds (OH-damage) in air contact [7]. Thus, it is necessary to replace the damaging, polar bonds by unpolar ones to decrease the $\mathrm{k}$-value again.

UV assisted thermal curing, the silylation process and the k-restore via hydrocarbon plasma were all tested as possible repair mechanisms [6]. Neither of the three repair mechanisms is ideally suited for porous ULK materials. For example, the UV assisted thermal curing can lead to the compression, if not the collapse, of porous materials [8]. This is due to the loss of $\mathrm{SiOH}$ groups and water molecules without replacements that re-stabilize the porous structure. Further, temperatures of about $600-1000^{\circ} \mathrm{C}$ are necessary to completely cure the damage [6], and thus incompatible with ULSI-CMOS technology.

The silylation process 9 13, on the other hand, works at much lower temperatures $\left(\mathrm{T}<300^{\circ} \mathrm{C}\right)$. However, due to the size of the silylation precursors they are not able to diffuse into deeper regions of the damaged material. Thus, the restore of the k-value is limited to the surface [14.

The third repair process uses hydrocarbon plasma. Small methane fragments are able to diffuse into the pores. However, experimental investigations show that the methane plasma fragments build a carbon rich layer on the surface [15. While this layer protects the ULK material from further damage [16], it does not repair the already existing damage. Therefore, an alternative in situ k-restore process is needed: The plasma repair process.

The main concept of this repair mechanism is to perform a plasma enhanced fragmentation of large silylation precursors $(6-9 \AA)$. The small fragments $(2.5-5 \AA)$ can diffuse deeper into the pores than the silylation precursors do, while maintaining their good repair behavior. The repair temperature has to be low $\left(\mathrm{T}<100^{\circ} \mathrm{C}\right)$ to protect the material from thermal damage.

We show an overview of the considered repair fragments and their assumed repair reactions in figure 1 . It is visible that the repair fragments must contain at least one oxygen atom to cure an $\mathrm{H}$-damage. To cure an $\mathrm{OH}$-damage, the silicon atom of the repair fragments must possess at least one dangling bond. Depending on the number of oxygen atoms and dangling silicon bonds, the repair fragments are able to cure either an $\mathrm{OH}-$ or $\mathrm{H}$-damage, or both damage types. Further, the repair

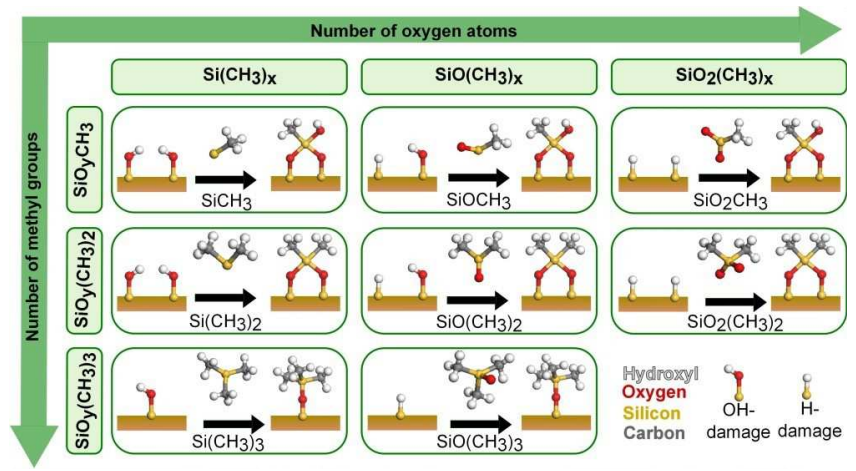

Figure 1. (Color online) Overview of possible repair reactions and all considered repair fragments. 


\begin{tabular}{|c|c|c|c|c|c|c|}
\hline Name & $\mathrm{SiH}_{3} \mathrm{OH}$ & $\mathrm{SiH}_{2} \mathrm{OH}$ & $\mathrm{SiH}_{2} \mathrm{OH}_{2}$ & $\mathrm{SiH}_{2}(\mathrm{OH})_{2}$ & $\mathrm{SiH}_{2} \mathrm{O}$ & $\mathrm{SiH}_{3} \mathrm{O}$ \\
\hline OH-damage & क & op & & & & \\
\hline \begin{tabular}{|l|} 
additional \\
damage
\end{tabular} & & & $\begin{array}{l}\mathrm{OH}_{2^{-}} \\
\text {damage }\end{array}$ & \begin{tabular}{|c|} 
double \\
OH-damage \\
\end{tabular} & & \\
\hline H-damage & 8 & $g=8$ & \&\& & & & है \\
\hline \begin{tabular}{|l|} 
closed/ \\
open shell
\end{tabular} & $\begin{array}{l}\text { closed } \\
\text { shell }\end{array}$ & $\begin{array}{l}\text { open } \\
\text { shell }\end{array}$ & $\begin{array}{l}\text { open } \\
\text { shell }\end{array}$ & $\begin{array}{l}\text { closed } \\
\text { shell }\end{array}$ & $\begin{array}{l}\text { closed } \\
\text { shell }\end{array}$ & $\begin{array}{l}\text { open } \\
\text { shell }\end{array}$ \\
\hline
\end{tabular}

Figure 2. (Color online) Overview of the studied ULKfragments and their damages. The damage region is highlighted in blue (OH-damage) and pink (H-damage).

molecules that contain exactly one methyl group are prone to further damage after the repair process, while the repair fragments with three methyl groups can only repair one damaged site.

\section{COMPUTATIONAL DETAILS}

We employed density functional theory (DFT) to study the repair fragments and their repair processes. The calculations were carried out using $\mathrm{Dmol}^{3}[17,18$ as implemented in Accelrys' Materials Studio (Version 6.0) 19] on the PBE/DNP(3.5)-level [17, 20. The energy convergence criterion for the geometry optimizations was $10^{-5}$ $\mathrm{Ha}(1 \mathrm{Ha}=1$ Hartree $=27.2114 \mathrm{eV}=2625.5 \mathrm{~kJ} / \mathrm{mol})$. Each selfconsistent field method (scf) cycle of the geometry optimization steps had a convergence criterion of $10^{-6} \mathrm{Ha}$. Thermal smearing up to $0.008 \mathrm{Ha}$ was employed for problematic convergence cases. The orbital cutoff was adjusted to $4.6 \AA$. We included the Grimme DFT-D correction. The reaction energies are calculated for a temperature of $0 \mathrm{~K}$.

\section{MODEL SYSTEM}

To study the repair behavior of the fragments, we composed a small set of ULK-fragments (refer figure 2). The approach to use fragments to study surface reactions has been successfully employed with regard to atomic layer deposition (ALD) processes [21] and was also applied to ULK materials by Böhm et al. [11, 23] .

Opposed to the ULK-fragment used by Böhm et al, our set of ULK-fragments represents various possible states of silicon and oxygen in the damaged ULK material. Besides closed shell fragments, also open shell fragments were taken into consideration to present under- and overcoordinated silicon and oxygen atoms. With these five ULK-fragments four different damage types can be studied: An $\mathrm{H}$-damage, an $\mathrm{OH}$-damage, a double $\mathrm{OH}$-damage and an $\mathrm{OH}_{2}$-damage, as visualized in figure 2 .

All atoms outside the highlighted region in figure 2 were fixed during geometry optimizations. The exception

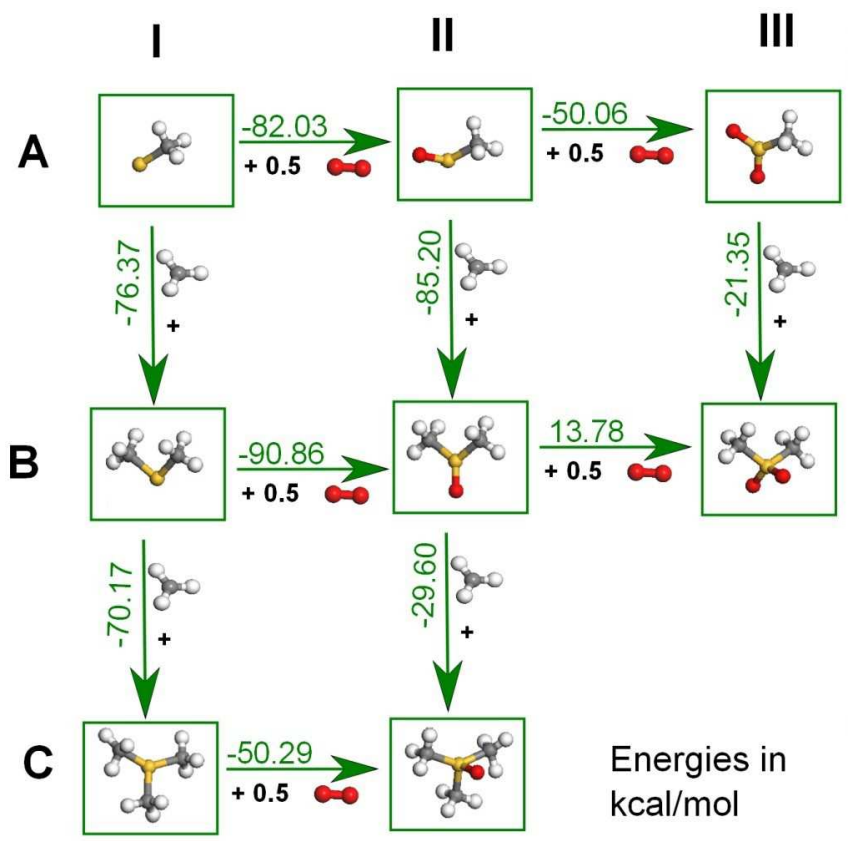

Figure 3. (Color online) Selected reactions of the repair fragments. From left to right the energy for the addition of one oxygen atom to the fragment is shown. From top to bottom the addition energy for one methyl groups is displayed.

is the ULK-fragment $\mathrm{SiH}_{2}(\mathrm{OH})_{2}$ whose second hydroxyl group was fixed when representing a single $\mathrm{OH}$-damage. A fast screening of the effectiveness of the considered repair fragments from figure 1 was performed with these five ULK-fragments.

\section{RESULTS AND DISCUSSION}

There are many silylation precursors available, which could be used as the basis for the plasma repair process. To study all possible fragmentation reactions would be far beyond the scope of this paper. However, today's silylation precursors like octamethylcyclotetrasiloxane (OMCTS), bis(dimethylamino)-dimethylsilane (DMADMS) and hexamethyldisilazane (HMDS) [24, 25] would fragment to at least one of our considered repair fragments (figure 1), as they all consist of at least one silicon atom and one methyl group. Thus, possible transformation reactions between our considered repair fragments and the involved reaction energies are shown in a systematic way in figure 3 .

The reactions shown are sufficient to demonstrate the predominance of one repair fragment over the other. In detail, the reaction paths I to III are highly exothermic and indicate that larger repair fragments with three methyl groups are preferential. Thus, it is unlikely to find repair fragments that are prone to damages themselves (see the group $\mathrm{SiO}_{y} \mathrm{CH}_{3}$ in Fig. 1). Further, reactions A to $\mathrm{C}$ demonstrate that (in most cases) oxygen containing 


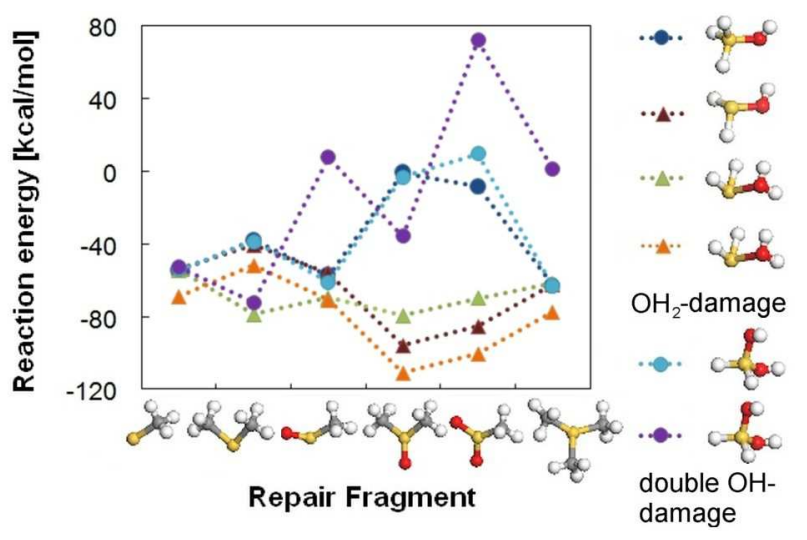

Figure 4. (Color online) $\mathrm{OH}-$, double $\mathrm{OH}-$ and $\mathrm{OH}_{2}$-repair reactions. The ULK-fragments represented by dots are closed shell fragments, whereas the open shell ULK-fragments are displayed by triangles in the diagram. The dotted lines are only a guide for the eyes and show no correlations.

repair fragments are energetically favored. Finally, we exemplarily study the reaction from A-II to C-I to investigate the effect of replacing one oxygen atom by two methyl groups. On the basis of the strongly exothermic reaction energy of $-64.51 \mathrm{kcal} / \mathrm{mol}$, it can be seen that two methyl groups are more effective than one oxygen atom. In short, under the condition of a methyl rich atmosphere, $\mathrm{SiO}\left(\mathrm{CH}_{3}\right)_{3}$ will be the dominant repair fragment for oxygen containing silylation precursors, while oxygen-free silylation precursors will lead to $\mathrm{Si}\left(\mathrm{CH}_{3}\right)_{3}$.

Next, we analyzed the repair effect of the repair fragments. We first investigated their reaction with all ULKfragments from figure 2 that represent an $\mathrm{OH}$-damage. The resulting reaction energies of these repair processes of an $\mathrm{OH}-$, double $\mathrm{OH}$ - and $\mathrm{OH}_{2}$-damage are shown in figure 4

The main conclusion that can be drawn from the studied OH-repair reactions is that the reaction energy is strongly dependent on the open shell or closed shell nature of the ULK-fragments. While the repair fragment $\mathrm{Si}\left(\mathrm{CH}_{3}\right)_{3}$ displays the best repair effect for closed shell fragments, it is only a mediocre repair fragment for open shell ULK-fragments. The open shell fragments instead favor oxygen containing repair fragments, with $\mathrm{SiO}\left(\mathrm{CH}_{3}\right)_{2}$ being the best suited fragment for the $\mathrm{OH}$ repair.

The reason for this different repair tendencies lies in the presence of one dangling Si-bond in the open shell ULK-fragments. One dangling Si-bond, together with the oxygen atom of the $\mathrm{OH}$-damage forms an energetically favorable diamond-shaped $\mathrm{SiO}$-center with the oxygen containing repair fragments. In the closed shell ULKfragments, the lack of a dangling Si-bond together with the saturating hydrogen atoms prevent the formation of this energetically favored shape (see figure 5 a).

The number of dangling Si-bonds also plays an important role in the repair of a double $\mathrm{OH}$-damage. Because
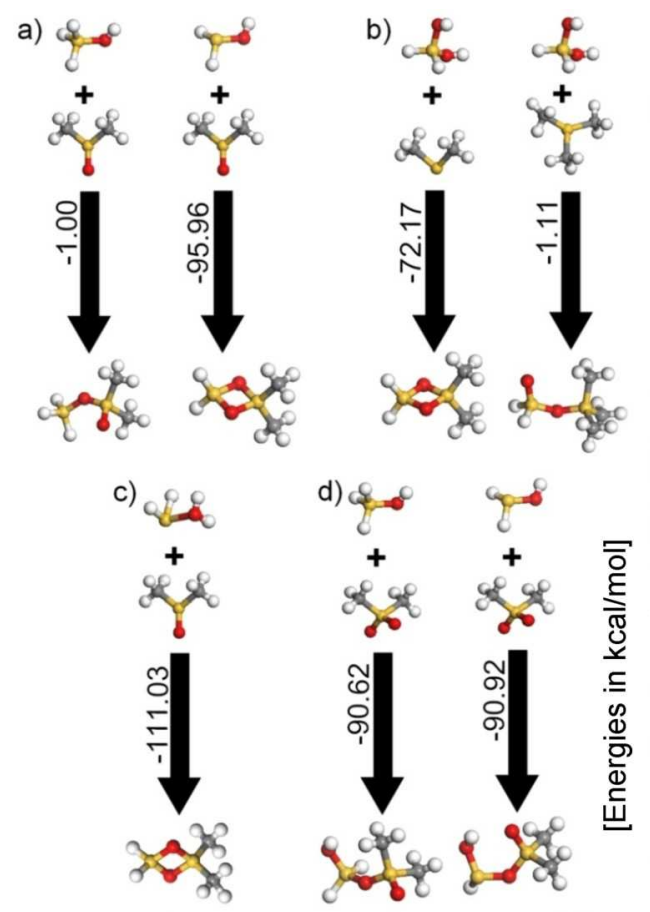

Figure 5. (Color online) Exemplary repair reactions for a) $\mathrm{OH}$-damage for $\mathrm{SiH}_{3} \mathrm{OH}$ (closed shell, left) and $\mathrm{SiH}_{2} \mathrm{OH}$ (open shell, right), b) double $\mathrm{OH}$-damage, c) $\mathrm{OH}_{2}$-damage and d) $\mathrm{H}$-damage for $\mathrm{SiH}_{3} \mathrm{OH}$ (closed shell, left) and $\mathrm{SiH}_{2} \mathrm{OH}$ (open shell, right). The desorbed $\mathrm{H}_{2}$ molecule is not displayed.

the repair of one $\mathrm{OH}$-damage demands exactly one dangling Si-bond in the repair fragment, $\mathrm{Si}\left(\mathrm{CH}_{3}\right)_{2}$ is the most effective repair fragment for this damage type. Further, the two oxygen atoms of the double $\mathrm{OH}$-damage are able to form the energetically favorable diamond-shaped SiOcenter with $\mathrm{Si}\left(\mathrm{CH}_{3}\right)_{2}$ as illustrated in figure $5 \mathrm{~b}$. For the majority of the other considered repair fragments, the repair process is endothermic due to the lack of reactive Si-bonds.

The repair of an $\mathrm{OH}_{2}$-damage, on the other hand, is strongly exothermic for all repair fragments because the formation of water is energetically favorable. As all other open shell ULK-fragments of this damage type also prefer oxygen-containg repair fragments over oxygen-free ones, they lead to the diamond-shaped $\mathrm{SiO}-$ center (see figure 5).

Next, we used the ULK-fragments from figure 2 to study the repair of an $\mathrm{H}$-damage and show the results in figure 6. Here, no dependency on the closed shell or open shell nature is apparent. Figure 5d illustrates that for these reactions no diamond-shaped $\mathrm{SiO}$-center is formed because of the fixed position of the saturating OH-group/oxygen atom in the ULK-fragments. The most effective repair fragments for the repair of the $\mathrm{H}$ damage are: $\mathrm{SiO}_{2} \mathrm{CH}_{3}, \mathrm{SiO}_{2}\left(\mathrm{CH}_{3}\right)_{2}$ and $\mathrm{SiO}\left(\mathrm{CH}_{3}\right)_{3}$.

In a final step we combine our findings of the most effective repair fragments with the dominant repair fragments that can be gained from the fragmentation of sily- 


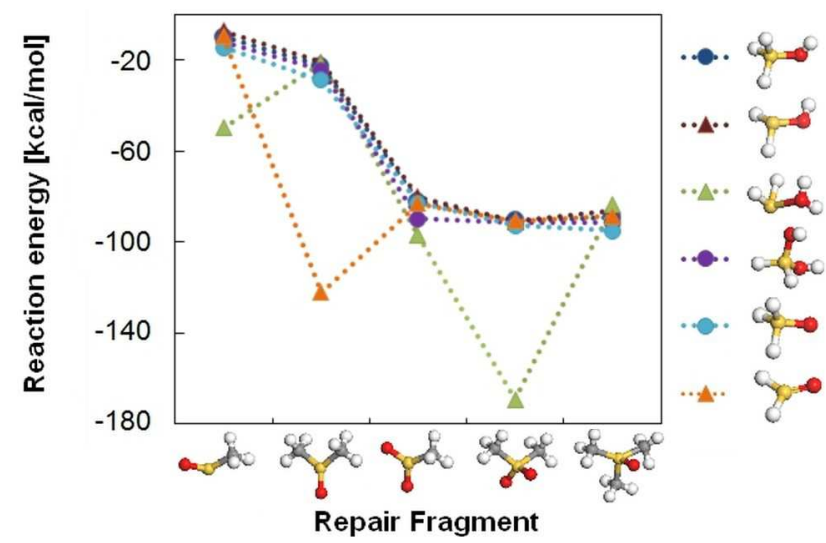

Figure 6. (Color online) H-repair of the ULK-fragments. The ULK-fragments represented by dots are closed shell fragments, whereas the open shell ULK-fragments are displayed by triangles in the diagram. The dotted lines are only a guide for the eyes and show no correlations.

lation precursors in a methyl-rich atmosphere. Based on these studies, we can state that the dominant repair fragments $\mathrm{SiO}\left(\mathrm{CH}_{3}\right)_{3}$ and $\mathrm{Si}\left(\mathrm{CH}_{3}\right)_{3}$ are among the best suited repair fragments for the $\mathrm{OH}$ - and $\mathrm{H}$-damage when a closed shell ULK-fragment is used which may represent the extended solid best. This means that the fragments of silylation precursors will be able to successfully cure $\mathrm{H}-, \mathrm{OH}-$, double $\mathrm{OH}-$ and $\mathrm{OH}_{2}$-damages. However, the general preference for large repair fragments leads to a steric hindrance that could prevent the repair of other damages in close vicinity and thus no full repair of the damaged material will be achieved.

We find it possible that spatial and electronic confinements in real pores are likely to prevent the formation of the energetically favorable diamond-shaped SiO-center. This assumption is based on the behavior of the closed shell ULK-fragments and the repair of H-damages. In both cases the space accessible for the oxygen atom is restricted either by steric hindrance from the $\mathrm{H}$-atoms or because of its fixed position. This prevents the oxygen atom from getting in the bonding range of the repair fragment's $\mathrm{SiO}$-group, and thus no energetically favored diamond-shaped SiO-center can be formed. This kind of restriction in the movement of oxygen will also occur in the bulk material, where oxygen is already bound to one silicon atom [26.

\section{CONCLUSION}

We have successfully demonstrated that the plasma repair process is able to repair both $\mathrm{H}$ - and $\mathrm{OH}$-damages and summarize our findings in figure 7 . The best repair fragments for the repair of $\mathrm{OH}$-damages possess the same amount of dangling bonds as $\mathrm{OH}$-damages that have to be repaired. And oxygen atoms are needed to repair Hdamages.

Thus, we can say that the suggested plasma repair process based on fragmented silylation precursors is a suitable alternative repair process for damaged ULK materials. We expect that the final repair behavior of the plasma repair process will depend on the chosen silylation precursor. For example, a non-oxygen containing silylation precursor will be less effective than an oxygen containing one, as it is not be able to cure H-damages due to the missing oxygen atoms.
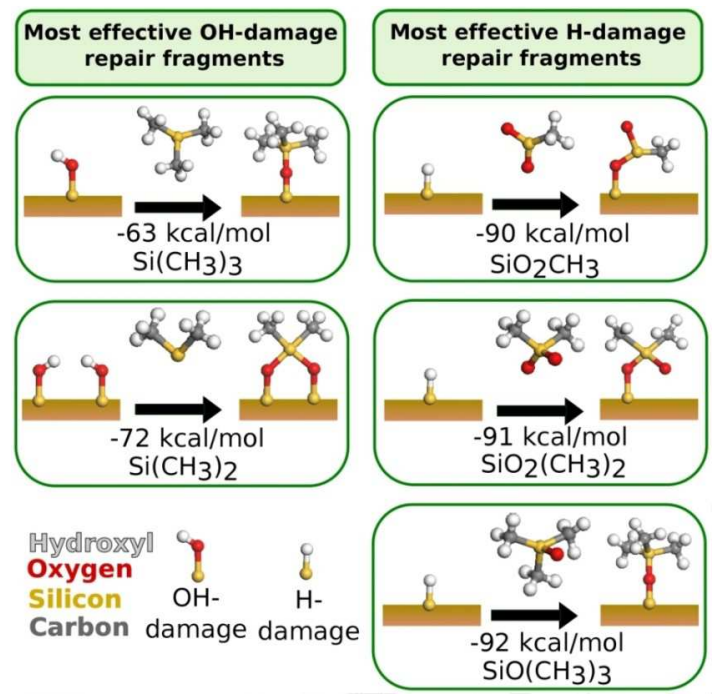

Figure 7. (Color online) Summary of the findings. The best suited repair fragments for the repair of an $\mathrm{OH}-$, double $\mathrm{OH}$, and H-damage are displayed. The energies are the results from the ULK-fragment $\mathrm{SiH}_{2}(\mathrm{OH})_{2}$.

\section{ACKNOWLEDGMENTS}

S. Gemming acknowledges funding from the Initiative and Networking Funds of the President of the Helmholtz Association via the W3 program. C. Wagner acknowledges the funding by the DFG research unit 1713 "Sensoric Micro- and Nanosystems".
[1] www.itrs.net (2013).

[2] M. Baklanov, P. S. Ho and E. Zschech, Advanced In- terconnects for ULSI Technology, 1st ed. (John Wiley \& Sons, New York, USA, 2012). 
[3] A.Grill and V. Patel, Appl. Phys. Lett. 79, 803 (2001).

[4] A.Grill and V. Patel, J. Appl. Phys. 104, 024113 (2008).

[5] M. Baklanov, K. Maex and M. Green, Dielectric films for advanced microelectronics, 1st ed. (John Wiley \& Sons, New York, USA, 2007).

[6] M. R. Baklanov, J.-F. de Marneffe, D. Shamiryan, A. M. Urbanowicz, H. Shi, T. V. Rakhimova, H. Huang and P. S.Ho, J. Appl. Phys. 113, 041101 (2013).

[7] T. Oszinda, M. Schaller, D. Fischer, C. Walsh and S. E. Schulz, Microel. Eng. 87, 457 (2010).

[8] H. Ren, G. A. Antonelli, Y. Nishi and J. L. Shohet, J. Appl. Phys. 108, 094110 (2010).

[9] T. Oszinda, M. Schaller and S. E. Schulz, J. Electrochem. Soc. 157, H1140 (2010).

[10] H. Shi, PhD thesis, The University of Texas at Austin, http://repositories.lib.utexas.edu/ bitstream/handle/2152/ETD-UT-2010-05-749/ SHI-DISSERTATION .pdf (2001).

[11] O. Böhm, R. Leitsmann, P. Plänitz, C. Radehaus, M. Schreiber and M. Schaller, J. Phys. Chem. A115, 8282 (2011).

[12] O. Böhm, R. Leitsmann, P. Plänitz, T. Oszinda, M. Schaller and M. Schreiber, Microel. Eng. 112, 63 (2013).

[13] N. Azizia and M. R. Saidi, Organometallics 23, 1457 (2004).

[14] T. Oszinda, PhD thesis, TU Chemnitz, http: //publica.fraunhofer.de/eprints/urn:nbn:de: 0011-n-1971787.pdf (2012).

[15] J. Bao, H. Shi, J. Liu, H. Huang, P. Ho, M. D. Goodner,
M. Moinpour and G. M. Kloster, International Interconnect Technology Conference, IEEE 2007, 147 (2007).

[16] H.-S. Lu, K. Gottfried, N. Ahner, S. Schulz and X.P. Qu, International Interconnect Technology Conference and 2011 Materials for Advanced Metallization (IITC/MAM), IEEE 2011, 1 (2011).

[17] B. Delly, J. Chem. Phys. 92, 508 (1990).

[18] B. Delly, J. Chem. Phys. 113, 7756 (200).

[19] Accelrys Software Inc., Materials Studio Release Notes, Release 6.0, San Diego Accelrys Software Inc., (2011).

[20] J. P. Perdew, K. Burke and M. Ernzerhof, Phys. Rev. Lett. 77, 3865 (1996).

[21] Y. Widjaja and C. B. Musgrave, Appl. Phys. Lett. 80, 3304 (2002).

[22] O. Böhm, R. Leitsmann, P. Plänitz, C. Radehaus, M. Schaller and M. Schreiber, Comp. Theor. Chem 991, 44 (2012).

[23] O. Böhm, R. Leitsmann, P. Plänitz, C. Radehaus, M. Schaller and M. Schreiber, Comp. Theor. Chem 991, 44 (2012).

[24] H. Chaabouni, L. Chapelon, M. Aimadeddine, J. Vitiello, A. Farcy, R. Delsol, P. Brun, D. Fossati, V. Arnal, T. Chevolleau, O. Joubert and J. Torres, Microel. Eng. 84, 2595 (2007).

[25] T. Fischer, N. Ahner, S. Zimmermann, M. Schaller and S. Schulz, Microel. Eng. 92, 53 (2012).

[26] A. Förster, C. Wagner, J. Schuster and S. Gemming. Microel. Eng. (2015) submitted manuscript. 